\title{
Application of sodium salicylate up-regulates defense response against Fusarium graminearum in wheat spikes
}

\author{
M. SORAHINOBAR ${ }^{1}$, V. NIKNAM ${ }^{1,5 *}$, A. JAHEDI ${ }^{2}$, H. EBRAHIMZADEH $^{1}$, B. MORADI ${ }^{1}$, \\ M. BEHMANESH ${ }^{3}$, and H. SOLTANLOO ${ }^{4}$
}

\author{
Department of Plant Biology, School of Biology, College of Science, University of Tehran, 1417466191, \\ Tehran, $\operatorname{Iran}^{1}$ \\ Department of Plant Pathology, Tarbiat Modares University, 1411713116, Tehran, Iran ${ }^{2}$ \\ Department of Genetic, School of Biological Sciences, Tarbiat Modares University, 1411713116, Tehran, Iran ${ }^{3}$ \\ Department of Plant Breeding and Biotechnology, Gorgan University of Agricultural Sciences and Natural \\ Resources, 4918943464, Gorgan, Iran ${ }^{4}$ \\ Center of Excellence in Medicinal Plant Metabolites, Tarbiat Modares University, 1411713116, Tehran, Iran ${ }^{5}$
}

\begin{abstract}
Fusarium head blight caused by the hemibiotrophic fungus Fusarium graminearum is one of the most devastating diseases of wheat which reduces both grain yield and quality. To better understand mechanism underlying wheat resistance to this pathogen, the expressions of five candidate genes encoding phenylalanine ammonia-lyase (PAL), glucanase-2 (Gl 2), class IV chitinase (Cht-4), cytochrome $P_{450}\left(C Y P_{)}\right.$, and pleiotropic drug resistance $(P D R)$ following spike inoculation with F. graminearum was compared in susceptible cv. Falat and resistant cv. Sumai3 at three time points $(48,96,144 \mathrm{~h}$ after inoculation). Real-time quantitative PCR analysis indicated earlier and greater inductions of PAL, Glu-2, and Cht-4 in spikes of 'Sumai3' as compared to 'Falat' in response to F. graminearum inoculation. The expression of $C Y P$ in the resistant 'Sumai3' was about three times higher than in 'Falat' at $144 \mathrm{~h}$ after pathogen inoculation. Moreover, soil drench application of sodium salicylate (SA) one day before pathogen inoculation drastically curtailed pathogen infection in both the cultivars. Furthermore, SA treatment caused an induction of these genes in spikes of the susceptible cultivar to show a similar pattern as in the resistant one when inoculated with F. graminearum. Proteomics analysis of F. graminearum treated spikes $96 \mathrm{~h}$ after inoculation confirmed an increase of Glu and Cht spot volume in 'Sumai3' whereas a decrease in 'Falat'. The SA treatment also caused significant increases in Glu and Cht spot volumes in both the cultivars. Our findings show an association between SA improvement of wheat defense against $F$. graminearum infection and induction of genes encoding proteins involved in pathogen response ( $G l u-2, C h t-4)$, secondary metabolite biosyntheses $(P A L)$, and xenobiotic detoxification $(C Y P$ and $P D R)$.
\end{abstract}

Additional key words: Cht-4, CYP, fusarium head blight, Glu-2, resistance, PAL, PDR, Triticum aestivum.

\section{Introduction}

Plants have evolved complex defense strategies to confront pathogen invasion. Based on the way that pathogens are detected by plants, there is a two-branched innate immune system: pathogen associated molecular pattern (PAMP)triggered immunity (formerly called basal resistance) and effector-triggered immunity (formerly termed gene mediated resistance) (Jones and Dangl 2006). Both PAMPtriggered immunity and effector-triggered immunity can trigger salicylic acid accumulation, expression of pathogenesis-related (PR) genes, and systemic acquired resistance, which provides protection against a broad range of pathogens (Dempsey et al. 2011). A number of studies indicated that salicylic acid signaling pathway is required for resistance against biotrophic and hemi-biotrophic

Submitted 19 September 2015, last revision 1 April 2019, accepted 16 April 2019.

Abbreviations: Cht-4 - class IV chitinase; CYP - cytochrome $\mathrm{P}_{450}$; hai - hours after inoculation; DON - deoxynivalenol; FHB - fusarium head blight; Glu - glucanase-2; MPR - multidrug resistance-associated protein; PAL - phenylalanine ammonia-lyase; PAMP - pathogen associated molecular pattern; PDR - pleiotropic drug resistance; PR - pathogenesis-related; SA - sodium salicylate.

Acknowledgements: We are most grateful to Dr. Ralph Kissen from the Department of Biology, Norwegian University of Science and Technology, Trondheim, Norway and Prof. Jyoti Shah from the Department of Biological Science, University of North Texas, USA for the constructive comments and English language editing.

* Corresponding author; e-mail: vniknam@khayam.ut.ac.ir 
pathogens; on the other hand, to combat necrotrophic pathogens, plants activate mainly the jasmonic acid and ethylene signaling pathways (Makandar et al. 2012). Fusarium graminearum as a hemi-biotrophic pathogen is the major causative agent of fusarium head blight (FHB) in the world. The FHB is a main disease of wheat in different areas of Iran such as Mazandaran, Gorgan and Moghan regions (Moosawi-Jorf et al. 2007). The pathogen produces mycotoxins such as deoxynivalenol (DON), that are harmful if consumed by humans and animals (Bai and Shaner 2004). Therefore, a great deal of interest has been paid to food safety improvement through study of FHBresistant cultivars. Several studies indicated that salicylic acid sprayed onto wheat spikes is ineffective and does not contribute to FHB resistance (Yu and Muehlbauer 2001, Li and Yen 2008). Makandar et al. (2012) showed that suitable application of salicylic acid regulates basal resistance to $F$. graminearum in wheat; however, the exact mechanisms have not yet been clearly elucidated.

In our previous study, we showed that $F$. graminearum inoculation results in higher accumulations of salicylic acid, callose, phenolic compounds, peroxidase, phenylalanine ammonia lyase (PAL), and polyphenol oxidase in resistant (Sumai3) versus susceptible (Falat) wheat cultivars at $4 \mathrm{~d}$ after inoculation, when the first symptoms of infection appear. Moreover, sodium salicylate (SA) treated plants show a significant increment in hydrogen peroxide production and lipid peroxidation (Sorahinobar et al. 2016). To better understand the role of several genes involved in resistance against $F$. graminearum, we aimed to investigate the the expression patterns of genes encoding phenylalanine ammonia-lyase (PAL), glucanase-2 (GLU 2), class IV chitinase (Cht-4), cytochrome $P_{450}$ $(C Y P)$, and pleiotropic drug resistance $(P D R)$ in 'Falat' and 'Sumai3' inoculated with this pathogen. The $P A L$, Cht-4, and Glu-2 were selected because of their wellknown role in secondary metabolite biosyntheses and in hydrolyzation of fungal cell wall. The $C Y P$ and $P D R$ are noticeable for their roles in detoxification of xenobiotics including mycotoxins produced by pathogens in plants (Mitterbauer and Adam 2002, Li et al. 2010). To elucidate the potential role of salicylic acid on the response of these genes, the effect of soil drench application of SA on the expression of these genes was also evaluated, both without and with $F$. graminearum inoculation.

\section{Materials and methods}

Plants, growth, and treatments: Two wheat (Triticum aestivum L.) cultivars were used in this study: a susceptible Iranian spring cultivar Falat and a resistant Chinese spring cultivar Sumai3. Seeds were germinated in autoclaved compost-peat-based planting mixture (five seeds per $2-\mathrm{dm}^{3}$ plastic pot). Wheat plants were grown in a greenhouse at day/night temperatures of $22 / 18^{\circ} \mathrm{C}$, a 16 -h photoperiod, an irradiance of $70 \mu \mathrm{mol} \mathrm{m} \mathrm{m}^{-2} \mathrm{~s}^{-1}$, and an air humidity of 40-60\%.

To prepare inoculums, the spores of Fusarium graminearum isolate $\mathrm{F} 42$ were derived from wheat grains, which were gathered from wheat production areas in Gorgan County, Golestan Province, Iran. They were cultured on potato dextrose agar in the dark at $25^{\circ} \mathrm{C}$ for $7 \mathrm{~d}$. In order to prepare suspension, the fungus was further grown in mung bean broth (i.e., $4 \mathrm{~g}$ of mung beans boiled in $100 \mathrm{~cm}^{3}$ of water) at a temperature of $22^{\circ} \mathrm{C}$ for $2 \mathrm{~d}$ (Makandar et al. 2006). The conidial suspension was adjusted to $10^{5}$ spores $\mathrm{cm}^{-3}$.

Point inoculation of wheat spikelets took place with $10 \mathrm{~mm}^{3}$ of the spore suspension or mock (mung bean broth) between the palea and lemma at the anthesis stage (six to seven weeks after germination). A pair of spikelets was inoculated in approximately the middle of the spike. Moisture zip-lock bags were used to cover the inoculated spikes and were removed $3 \mathrm{~d}$ after the inoculation.

Treatments with SA were done as described by Makandar et al. (2012). Briefly, pots were left at room temperature to get soil in a semi-dry state, but the plants did not wilt, and then $500 \mathrm{~cm}^{3}$ of $200 \mu \mathrm{M}$ sodium salicylate (Sigma-Aldrich, St. Louis, MO, USA) was added. Pretreatment of wheat with SA was done $1 \mathrm{~d}$ before $F$. graminearum inoculation. Control plants were irrigated with water in the same pattern.

For assay, 54 pots including 5 plants were prepared for each cultivar. They were divided into four sets: 1) plants irrigated with water and inoculated with mock; 2) plants irrigated with water and inoculated with F. graminearum; 3) plants irrigated with $200 \mu \mathrm{M}$ SA and inoculated with mock; 4) plants irrigated with $200 \mu \mathrm{M}$ SA and subsequently inoculated with $F$. graminearum after $24 \mathrm{~h}$.

Following inoculation with $F$. graminearum, the disease symptoms on wheat spikelets in both the cultivars with or without SA treatment were monitored for $28 \mathrm{~d}$, and at periodic intervals, the number of infected spikelets was assessed for FHB disease (Makandar et al. 2012). Each time point sample consisted of 40 plants with 3 replicate samples per time point. The same procedures were adopted for the control plants. The Student $t$-tests were used to reveal statistically significant differences $(P \leq 0.05)$ in visual symptoms among the different samples.

Real-time quantitative PCR analysis: Tissue samples were collected at 48, 96, and $144 \mathrm{~h}$ after inoculation (hai). The experiment was repeated 3 times per time point, and at each time point, the sample consist of at least 40 spikes for treatments or control. The spikelet tissue was pooled and ground into a fine powder in liquid nitrogen using a mortar and pestle. The total RNA was extracted using an $R N X$ plus kit (RN7713C, CinnaGen, Tehran, Iran) according to the manufacturer's instruction with a minor modification. The extracted RNA was quantified by a spectrophotometer and its quality was verified by $1 \%(\mathrm{~m} / \mathrm{v})$ agarose gel electrophoresis. The first-strand cDNA was synthesized by reverse transcription reaction with $3 \mu \mathrm{g}$ of purified total RNA using a Revert Aid $^{\mathrm{TM}}$ reverse transcriptase (Fermentas, Burlington, Canada), oligo dT18, and random hexamer primers ( $M W G$, Ebersberg, Germany) in a total volume of a reaction mixture of $20 \mathrm{~mm}^{3}$ according to the manufacturer's instructions. Forward and reverse 
primers for real-time quantitative PCR were designed by the PRIMER EXPRESS software (Applied Biosystems, Foster City, USA). Table 1 Suppl. shows properties and sequences of the primers for the genes of interest and the reference gene. Real-time quantitative PCR was performed using the Applied Biosystems 7500 real time PCR system with $10 \mathrm{ng}$ of cDNA, $10 \mathrm{~mm}^{3}$ of SYBR Green I master mix (Takara, Shiga, Japan), and $200 \mathrm{nM}$ forward and reverse primers up to final reaction volumes of $20 \mathrm{~mm}^{3}$ according to the manufacturer's instructions. The PCR cycle conditions were as follows: an initial denaturation at $95^{\circ} \mathrm{C}$ for 5 min followed by 40 cycles of denaturation at $95^{\circ} \mathrm{C}$ for $10 \mathrm{~s}$, annealing at $60^{\circ} \mathrm{C}$ for $30 \mathrm{~s}$, and extension at $72{ }^{\circ} \mathrm{C}$ for $30 \mathrm{~s}$. The specificity of primers for amplification was confirmed by melting-curve analysis and gelelectrophoretic analysis of the amplicon. The $\mathrm{Ct}$ values for all genes were normalized to the reference gene $\beta$-actin. The efficiency of each primer pair was determined using 10 -fold cDNA dilution series to reliably determine fold changes. Each sample was evaluated in three biological replicates. All gene expressions were expressed relative to the appropriate mock-inoculated controls. The Student $t$-tests were performed to reveal statistically significant differences $(P \leq 0.05)$ between samples. The mean of $\Delta \mathrm{Ct}$ for the two cultivars after treatment and control conditions was calculated, and finally the relative expression of genes was estimated as $2^{-\Delta \Delta \mathrm{Ct}}$ as described by Livak and Schmittgen (2001).

Protein extraction: Tissue samples for protein extraction were collected at 96 hai. Protein extraction was performed as described by Hurkman and Tanaka (1986) with some modifications. Briefly, plant material was ground in liquid nitrogen using a mortar and pestle. The resulting powder was transferred to a $10 \mathrm{~cm}^{3}$ tube. Then, $2.5 \mathrm{~cm}^{3}$ of extraction buffer containing $0.1 \mathrm{M}$ Tris- $\mathrm{HCl}(\mathrm{pH} 8.8)$, $10 \mathrm{mM} \mathrm{EDTANa} 2,0.4 \%(\mathrm{v} / \mathrm{v})$ 2-mercaptoethanol, and $0.9 \mathrm{M}$ sucrose, was added to each tube, and after brief vortexing, $2.5 \mathrm{~cm}^{3}$ of Tris ( $\mathrm{pH} \mathrm{8.8)} \mathrm{buffered} \mathrm{phenol} \mathrm{(Sigma,}$ St. Louis, MO, USA) was added. After vortexing at $4{ }^{\circ} \mathrm{C}$ for $30 \mathrm{~min}$, centrifugation was carried out in $5000 \mathrm{~g}$ and $4{ }^{\circ} \mathrm{C}$ for $10 \mathrm{~min}$. The upper phenol phase was carefully decanted and transferred to a new clean tube. These steps were repeated for the remaining aqueous phase by adding $2.5 \mathrm{~cm}^{3}$ of the Tris buffered phenol. Proteins in the collected phenol phase were precipitated by adding five volumes of pre-chilled $0.1 \mathrm{M}$ ammonium acetate in $100 \%$ methanol and incubated at $-20^{\circ} \mathrm{C}$. The precipitate was collected by centrifugation at $20000 \mathrm{~g}$ and $4^{\circ} \mathrm{C}$ for $20 \mathrm{~min}$. Finally, the pellet was washed 2 times with $0.1 \mathrm{M}$ ammonium acetate in methanol $(100 \%), 2$ times with ice-cold $80 \%(\mathrm{v} / \mathrm{v})$ acetone and finally once with cold $70 \%(\mathrm{v} / \mathrm{v})$ ethanol. After a brief air-drying, the protein pellet was re-suspended in lysis buffer containing $8 \mathrm{M}$ urea, $2 \mathrm{M}$ thiourea, $4 \%(\mathrm{w} / \mathrm{v})$ 3-[(3-cholamidopropyl)dimethylammonio]-1propanesulfonate, $50 \mathrm{mM}$ dithiotreitol, $35 \mathrm{mM}$ Tris, and $2 \%(\mathrm{v} / \mathrm{v})$ pharmalyte $(\mathrm{pH} 3-10)$. Total protein content was quantified according to Bradford (1976) using IgG as a standard.
Two-dimensional gel electrophoresis: The total protein extract $(200 \mu \mathrm{g})$ was loaded onto $17-\mathrm{cm}$ immobilized $\mathrm{pH}$ gradient (IPG) strips ( $\mathrm{pH} 3-10$, Bio-Rad, Hercules, CA, USA) during strip rehydration overnight. Isoelectric focusing was then performed for a total of $52 \mathrm{kVh}$ at $20^{\circ} \mathrm{C}$ using the Multiphore II system (Amersham Pharmacia Biotech, Uppsala, Sweden). The IPG strips were equilibrated according to the manufacturer's instruction in a solution containing $50 \mathrm{mM}$ Tris- $\mathrm{HCl}$ buffer, $\mathrm{pH} 8.8$, $6 \mathrm{M}$ urea, $30 \%(\mathrm{v} / \mathrm{v})$ glycerol, $2 \%(\mathrm{~m} / \mathrm{v})$ sodium dodecyl sulphate, $1 \%(\mathrm{~m} / \mathrm{v})$ dithiothreitol, and $0.002 \%(\mathrm{~m} / \mathrm{v})$ bromophenol blue. The second dimension was performed on a10 $\%(\mathrm{~m} / \mathrm{v})$ sodium dodecyl sulphate polyacrylamide gel using Protean Dodeca Cell (Bio Rad, Hercules, CA, USA) at $50 \mathrm{~V}$ for $30 \mathrm{~min}$ and then at $200 \mathrm{~V}$ and $4{ }^{\circ} \mathrm{C}$ for about $7 \mathrm{~h}$. The gels were stained using Coomassie brilliant blue according to Neuhoff et al. (1988). The images were analyzed using Progenesis Same Spots software (version 4.5, 2011; Nonlinear Dynamics, Durham, USA). Protein spots were characterized by matrix assisted laser desorption ionization-time of flight mass spectrometry (MALDI-TOF MS) and matched to proteins by querying mass spectra in a protein databases or the Triticeae EST translation database. The Student $t$-tests were performed to reveal statistically significant differences $(P \leq 0.05)$ between samples.

\section{Results}

In both the cultivars, the first symptoms of FHB infection

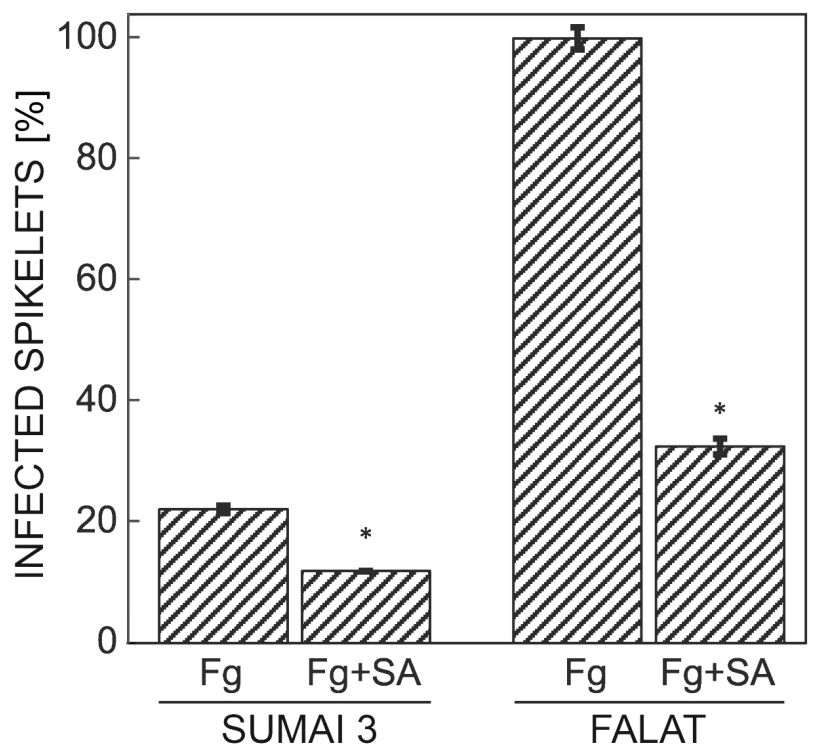

Fig. 1. Fusarium head blight disease rating monitored in wheat cvs. Sumai3 and Falat that were either irrigated with sodium salicylate (SA) $(200 \mu \mathrm{M})$ or with water (control treatment) $24 \mathrm{~h}$ before inoculation of spikes with Fusarium graminearum (Fg). Disease incidence was recorded at $28 \mathrm{~d}$ post-inoculation as the percentage of infected spikelets in each spike. Means \pm SE, $n=10, *$ - significant differences between control and treated samples $(P \leq 0.05 ; t$-test $)$. 


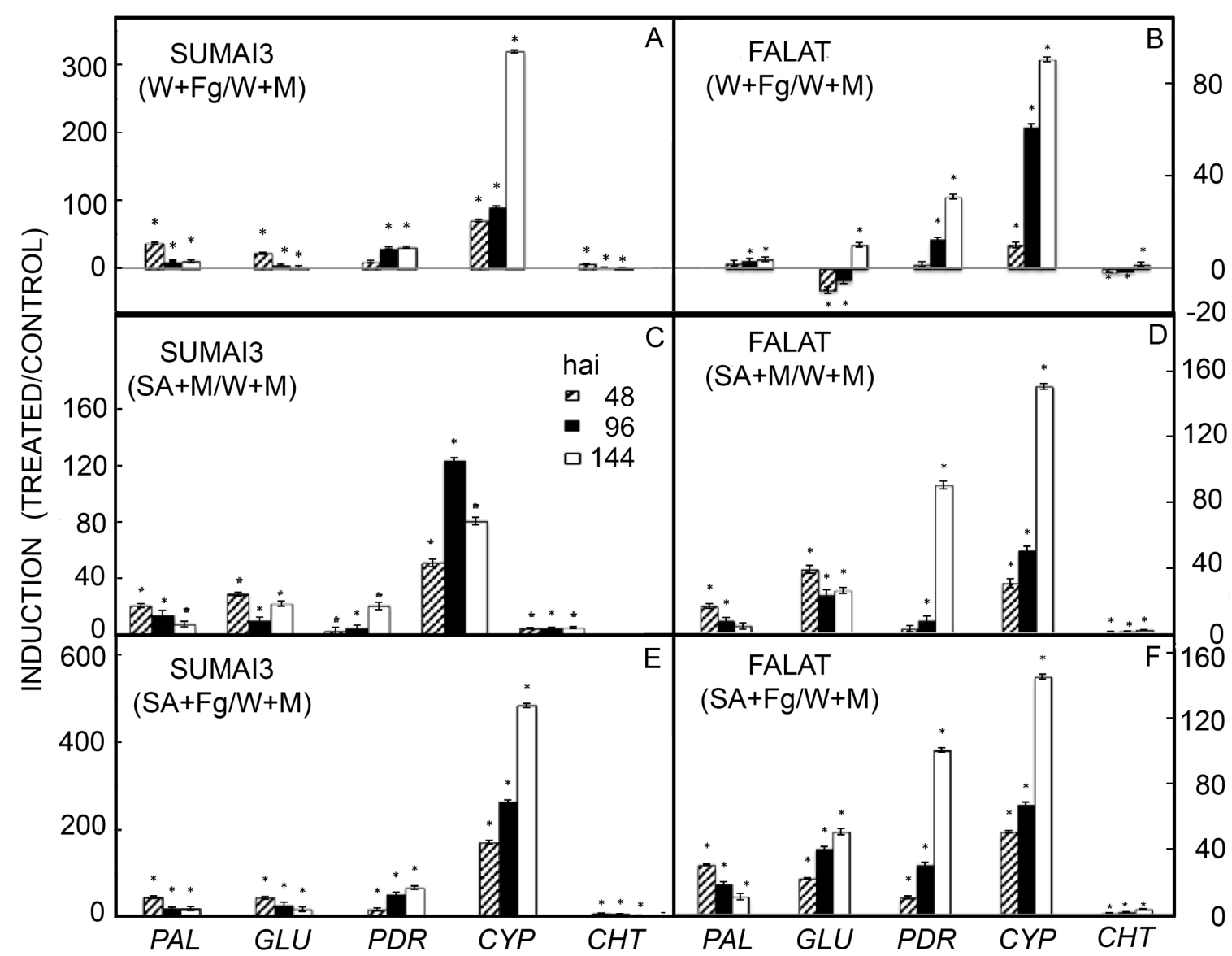

Fig. 2. Changes in transcriptions of defense-related genes in spikelets of fusarium head blight resistant (Sumai3) and susceptible (Falat) wheat at 48,96 , and $144 \mathrm{~h}$ after inoculation. Plants were either irrigated with water and inoculated with mock (W+M), irrigated with water and inoculated with Fusarium graminearum (W+Fg), irrigated with $200 \mu \mathrm{M}$ sodium salicylate (SA) and inoculated with mock $(\mathrm{SA}+\mathrm{M})$, or irrigated with $200 \mu \mathrm{M}$ SA and subsequently inoculated with $F$. graminearum $(\mathrm{SA}+\mathrm{Fg}$ ). Values were normalized to the wheat $\beta$-actin reference gene. Means \pm SEs, $n=3, *$ - significant differences between control and treated samples $(P \leq 0.05 ; t$-test $P A$ - phenylalanine ammonia lyase, GLU - glucanase-2, PDR - PDR-like ABC transporter, CYP - cytochrome $P_{450}$ monooxygenase, CHT - chitinase, hai - hours after inoculation.

appeared at 96 hai. Soil drench application of SA one day before inoculation curtailed FHB infection in 'Falat' and 'Sumai3' by about 70 and $10 \%$, respectively, as compared to their controls (Fig. 1). The appearance of symptoms at 96 hai provided a confirmation that the pathogen had penetrated the host tissues, and the infection was successful. Based on this, we considered the time points before and after 96 hai as pathogen biotrophic phase and necrotrophic phase, respectively. The time points of 48, 96, and 144 hai were selected to monitor plant gene responses to pathogen inoculation in both the phases.

The transcriptions of $G l u-2, C h t-4$, and $P A L$ in $F$. graminearum inoculated spikes of 'Sumai3' were higher $(P \leq 0.05)$ at 48 hai than at later time points (Fig. $2 A)$. In 'Falat', $P A L$ expression was somewhat induced whereas Glu-2 and Cht-4 expressions were repressed at 48 hai, however, all these genes were induced at 144 hai (Fig. 2B).

In general, all the assessed genes were more induced with F. graminearum in 'Sumai3' than in 'Falat' at early time points. Treatments with SA before inoculation drastically curtailed FHB effects. We also evaluated the effect of SA on the expressions of the same genes in mock inoculated spikelets. Following SA application, expressions of $P A L$, Glu-2, PDR, CYP, and Cht-4 were significantly $(P \leq 0.05)$ induced at least in two time points in both the genotypes (Fig. 2). This signified the role of SA in activation of these selected genes. It is noticeable, that the expressions of $P A L, G l u-2$, and Cht-4 show a distinctly different pattern in SA-pretreated 'Falat' compared to F. graminearuminoculated 'Falat'. It seems that SA treatment elicited changes in gene expressions in susceptible 'Falat' to result in a similar pattern as that in the resistant 'Sumai3' when inoculated with $F$. graminearum. Moreover, induction of most selected genes following SA irrigation was greater in 'Falat' compared to 'Sumai3' suggesting that 'Falat' may be more responsive to SA treatment than 'Sumai3' (Fig. 2).

To find interaction between $\mathrm{SA}$ as an exogenous elicitor and $F$. graminearum on wheat gene expressions, we assessed the expressions of selected genes in inoculated spikes of both the wheat cultivars following SA treatment $24 \mathrm{~h}$ before pathogen inoculation (Fig. 2). Interestingly, combined SA treatment and $F$. graminearum 

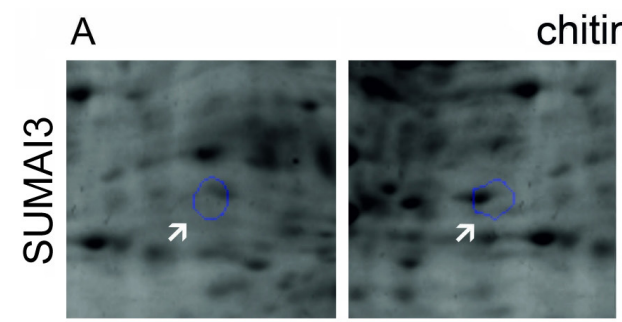

chitinase
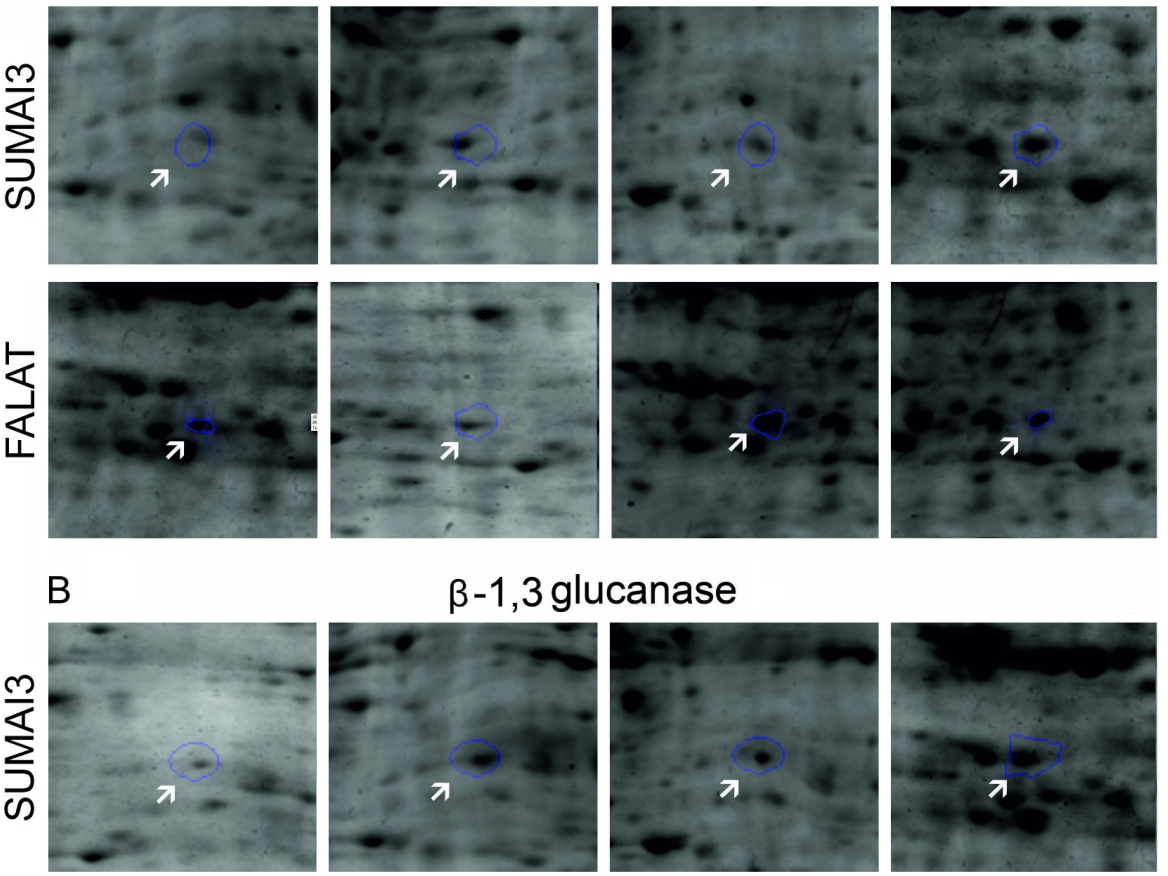

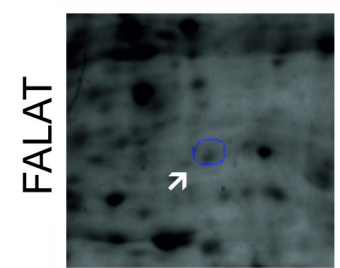

control

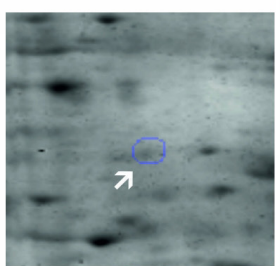

$\mathrm{Fg}$

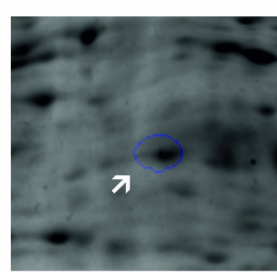

SA

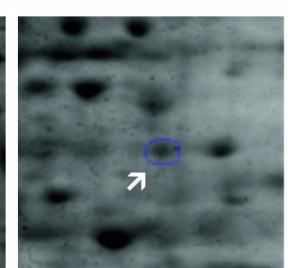

$\mathrm{Fg}+\mathrm{SA}$

Fig. 3. The $\beta$-1,3-glucanase and chitinase in spikelets of wheat fusarium head blight resistant (Sumai3) and susceptible (Falat) cultivars following either Fusarium graminearum inoculation (Fg), treatment with sodium salicylate (SA), or SA treatment one day before inoculation with $F$. graminearum (plants irrigated with $200 \mu \mathrm{M} \mathrm{SA}$ and inoculated with $F$. gramineareum, SA+Fg).

inoculation caused a strong induction of the expression of all five genes $(P \leq 0.05)$ at all three time points in both the cultivars compared with pathogen/mock-inoculated plants irrigated with water. Application of SA one day before $F$. graminearum inoculation led to a cumulative effect on $P D R$ and $C Y P$ gene expressions especially in 'Falat' (Fig. 2). Our findings show that the combined SA - F. graminearum treatment caused an earlier and stronger elevation of PAL in 'Falat' compared to inoculated 'Falat' without SA treatment. For both the cultivars, SA plus pathogen treatment elevated the expression of $P A L$ more than the SA treatment alone.

In summary, our observations indicate that F. graminearum inoculation resulted in alteration of defense gene expressions in both the cultivars, with a greater and/or earlier induction for most of the selected genes in the resistant 'Sumai3'. Moreover, application of SA effectively induced the expression of the same set of defense-related genes in both the genotypes, with a greater induction for most of them in 'Falat'

Analysis of two-dimensional electrophoresis gels gave several spots with variations in protein abundance between the treated and untreated controls in both cultivars (Fig. 3). Among identified proteins, significant changes in expressions of $\beta$-1,3-glucanase and chitinase in response to $F$. graminearum and SA treatment in both the cultivars were observed (Figs. 3 and 4). The spot volumes of chitinase and $\beta$-1,3-glucanase were significantly reduced after $F$. graminearum inoculation in susceptible 'Falat' whereas they increased in 'Sumai3'. Following application of SA in 'Falat', the spot volumes of chitinase and $\beta$-1,3-glucanase were induced about 1.5- and 2-folds, respectively, as compared to the control. Treatment with SA also caused an increase of these two spot volumes in 'Sumai3'. Combined SA and F. graminearum treatment caused a strong induction of 2.5-fold in chitinase expression in 'Sumai3' whereas no significant change was observed in 'Falat'. Similarly, this combined treatment significantly increased the spot volume of $\beta-1,3$-glucanase in 'Sumai3' but only a slight increase was observed in 'Falat' (Fig. 4). 


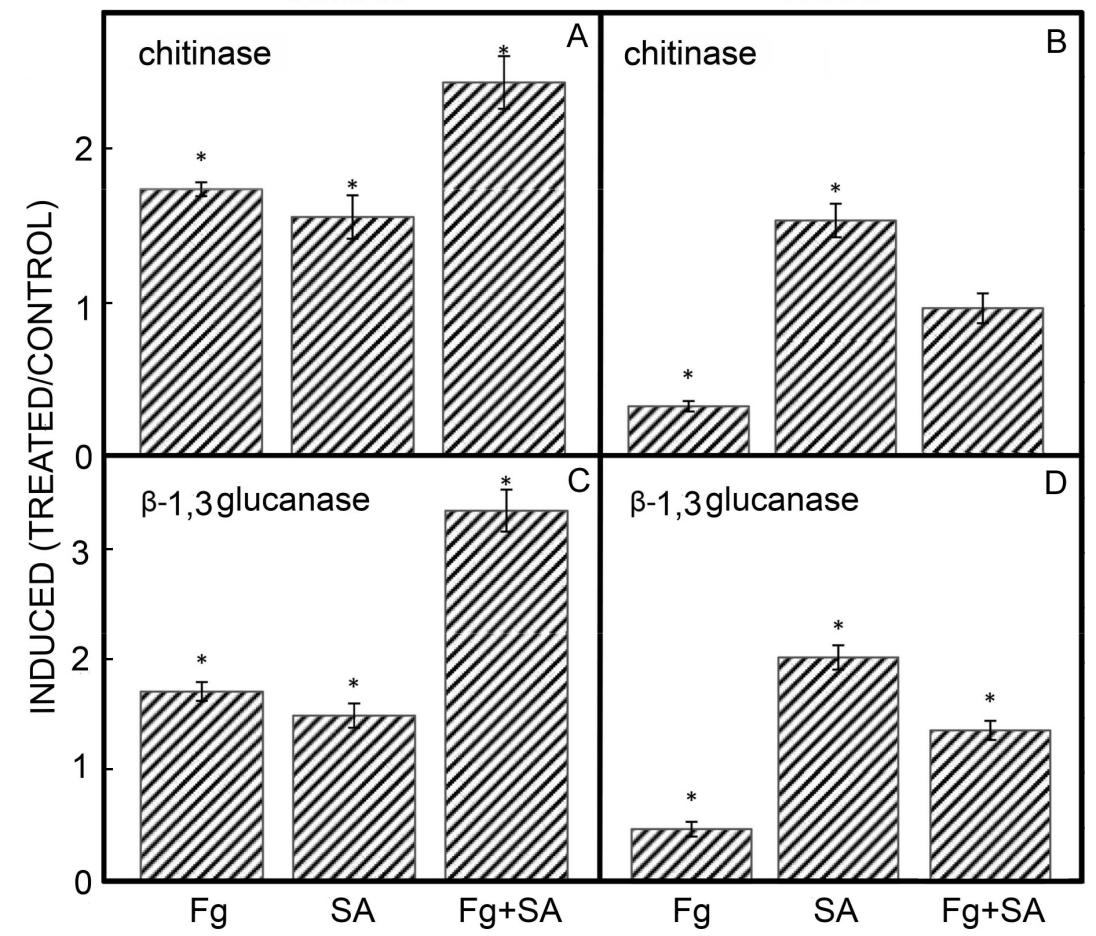

Fig. 4. The $\beta$-1,3-glucanase and chitinase in spikelets of fusarium head blight resistant (Sumai3) and susceptible (Falat) wheat cultivars following either Fusarium graminearum inoculation (Fg), treatment with sodium salicylate (SA), or SA treatment one day before inoculation with $F$. graminearum (plants irrigated with $200 \mu \mathrm{M}$ SA and inoculated with $F$. gramineareum, $\mathrm{SA}+\mathrm{Fg}$ ). Means $\pm \mathrm{SEs}, n=3$, *- significant differences between control and treated samples $(P \leq 0.05 ; t$-test $)$.

\section{Discussion}

Finding key regulator genes which give a plant the ability to react to a pathogen infection at the proper time and with enough power is very important. We analyzed the role of some genes involved in the phenylpropanoid pathway (PAL), pathogen cell wall degradation (Glu-2 and Cht-4), and mycotoxin detoxification $(P D R$ and $C Y P)$ in response to hemi-biotrophic pathogen $F$. graminearum inoculation at three time points during the early stages of infection.

Phenylalanine ammonia-lyase is known as the key enzyme in the entry point of the phenylpropanoid pathway. It is involved in the synthesis of several secondary metabolites and salicylic acid. The PAL is an inducible enzyme that responds to a variety of environmental stresses including wounding, nutrient depletion, UV irradiation, extreme temperatures, and biotrophic and hemi-biotrophic pathogens (Kim and Hwang 2014). Our study shows that genes involved in the salicylic acid pathway, $P A L$ and Glu 2, were more rapidly induced after inoculation in resistant 'Sumai3' as compared with the susceptible 'Falat'. In our previous study, we observed a significant induction in PAL activity in 'Sumai3' under both pathogen treatment and SA treatment (Sorahinobar et al. 2016). Our present results are also in accordance with a number of studies that provide evidence that PAL and the phenylpropanoid pathway play a role in the resistance of wheat to $F$. graminearum and deoxynivalenol (as the most important mycotoxin produced by to F. graminearum)
(Paranidharan et al. 2008, Ding et al. 2011).

Salicylic acid plays an important role in plant defense signaling, and it is required to establish a local resistance in the infected region as well as systemic resistance in the whole plant (Loake and Grant 2007). Silverman et al. (1995) showed that pathogen infection does not up-regulate salicylic acid content in rice, but other researchers (Savitch et al. 2007, Makandar et al. 2010) reported accumulation of salicylic acid in dicots under pathogen infection. These findings are also in accordance with our previous report of increased content of salicylic acid in a wheat resistant genotype under pathogen inoculation (Sorahinobar et al. 2016).

Our results imply that a rapid activation of the salicylic acid pathway could play an important role in $F$. graminearum resistance, and susceptibility may be related to delay in activation of this pathway. Our observation confirms that application of SA resulted in reduction of F. graminearum infection in both the wheat cultivars. Makandar et al. (2012) also showed that SA application plays an important role in basal resistance of wheat against $F$. graminearum. Hence, we investigated the effect of an exogenous application of SA on expressions of the above mentioned genes to get more insight into the networks and mechanisms involved in the complex nature of wheat resistance to FHB. As far as we know, this is the first study that has investigated the role of SA on some $F$. graminearum-inducible defense genes during the early stages of infection in resistant and susceptible 
wheat genotypes. The application of SA further increased the expression of $P A L$ in response to $F$. graminearum in the both the wheat cultivars. An induced expression of $P A L$ under application of salicylic acid was reported in different dicots as well (Fraissinet-Tachet et al. 1998, Thulke and Conrath 1998, Ding et al. 2002, Wen et al. 2005, Sadat Ejtahed et al. 2015). Moreover, in light of the fact that one route involved in the salicylic acid biosynthesis is through PAL (Vidhyasekaran 2015), it is anticipated that $P A L$ up-regulation through salicylic acid induction leads to salicylic acid synthesis, and there is a positive feedback loop of salicylic acid biosynthesis upon SA treatment. This finding is supported by our previous result of an augmented content of salicylic acid following SA application (Sorahinobar et al. 2016). We also found an induction of phenolic compounds in SA treated 'Sumai3' and 'Falat' (Sorahinobar et al. 2016). These metabolites can be used for cell wall rigidification and biosynthesis of phytoalexins (Dong 1998).

The $\beta$-1,3-glucanses and chitinases belong to PR proteins of the PR-2 and PR-3 families. Previous studies indicated that $\beta$-1,3-glucanases and chitinases have direct effects in defense against fungi by hydrolyzing fungal cell walls, which are mostly composed of chitin and $\beta$-1,3-glucans and consequently causes the lysis of fungal cells. In addition, $\beta$-1,3-glucanases and chitinases were shown to have an indirect effect on plant defense by releasing oligosaccharides from the hydrolysis of fungal cell walls, which acts as elicitors of defense reactions (Jia and Martin 1999) and thus serve as pathogen-associated molecular patterns (Nürnberger et al. 2004). Pathogenassociated molecular patterns detection by plants leads to induction of defense reactions including the accumulation of reactive oxygen species, production of PR proteins, strengthening of cell wall by oxidative cross-linking cell wall components, and the deposition of callose and lignin (Nürnberger et al. 2004). In the present study, induction of Glu-2 and Cht-4 expressions was much faster in the resistant cultivar than in the susceptible one, which is in agreement with previous reports on other plant-fungus systems (Van Kan et al. 1992, Rivera et al. 2002). The delayed expression of Glu-2 and Cht-4 in the susceptible cultivar might contribute to the reduced protection from the invading pathogen whereas the rapid expressions of Glu-2 and Cht-4 at the site of penetration in the resistant cultivar could play an important role in plant defense against FHB. In agreement with other studies (Bokshi et al. 2003), we also found a rapid significant induction of Glu-2 in susceptible 'Falat' following SA treatment. The possible role of this enzyme in systemic resistance of potato was highlighted by Woloshuk et al. (1991) showing its induction by Phytophthora infestans, a potato late blight pathogen. Hwang et al. (1997) also showed that induction of resistance to Phytophthora capsici in pepper plants by DL- $\beta$-amino-n-butyric acid treatment positively correlates with the accumulation of isoforms of $\beta-1,3$-glucanase and chitinase and endogenous salicylic acidin pepper stems.

Several studies have shown that acidic chitinases are induced by salicylic acid (Brederode et al. 1991, Buchter et al. 1997, Ancillo et al. 1999). In agreement with our study, Lawton et al. (1994) showed that in cucumber, the expression of class III Cht increases 10-fold following an application of SA. In our study, application of SA increased Cht -4 gene expression in both the cultivars. This suggests that $C h t-4$ expression could be part of a systemic acquired resistance response. Based on aforementioned studies, it seems that Glu and Cht genes show the same response to SA in monocots and dicots.

Our results show a higher induction of $C Y P$ in inoculated 'Sumai3' than in 'Falat'. Kong et al. (2005) showed that CYP709C3v2 is induced about 14-fold by $F$. graminearum infection compared to a water-treated control in a wheat resistant genotype. In addition, our results are similar to results obtained by Li et al. (2010) in wheat when challenged with $F$. asiaticum. In light of the fact that cytochrome $\mathrm{P}_{450}$ participates in various biochemical pathways including biosyntheses of some metabolites, cell wall components (lignin), signal molecules (salicylic acid), and plant defense compounds (Chapple 1998), our findings of a higher induction of CYP in inoculated 'Sumai3' can be interpreted as an attempt of the plant to resist against FHB. Moreover, some CYPs can metabolize xenobiotics produced by pathogens, such as mycotoxins, and convert them into nontoxic products. Walter et al. (2008) showed that treatment of wheat spikelets with DON causes accumulation of transcripts encoding two cytochrome $\mathrm{P}_{450}$ enzyme homologs. The late and higher up-regulation of $C Y P$ may be due to a delay in the production of tricotecenes (mycotoxins produced by Fusarium species) in the necrotrophic phase during the late stage of infection. Our results related to the effect of SA on CYP expression in F. graminearum inoculated plants show that application of SA can induce CYP expression in both the genotypes. Zhang et al. (2016) reported up-regulation of several CYPs and ATP-binding cassette transporters in Salvia miltiorrhiza in response to SA treatment.

In plants several genes such as $A B C$ transporters, multidrug resistance-associated proteins, and PDRs play major roles in detoxification processes (Kosaka et al. 2015). Pleiotropic drug-resistant protein transporters have been shown to be involved in plant defense, formation of the cuticular layer, and transport of antimicrobial terpenoids (Kang et al. 2010). It was known that PDR5like is a DON-resistant candidate gene, which disposes a fungal mycotoxin from cytoplasm (Mitterbauer and Adam 2002). In our study, up-regulation of a PDR-like $A B C$ transporter gene was shown in both the resistant and the susceptible cultivars following $F$. graminearum inoculation indicating a possible detoxification role of this gene. Our results are similar to results obtained by Bienert et al. (2012) showing that F. oxysporum causes induction of PDR in Nicotiana tabacum. Here, we also show that SA treatment caused induction of $P D R$ in both the cultivars with a higher induction in 'Falat' than in 'Sumai3'. Hence, our results suggest that pretreatment with SA may overcome susceptibility by activating the detoxification mechanism.

Gottwald et al. (2012) showed that the expressions of genes encoding ABC transporters, which are potentially involved in the detoxification of pathogen toxins, are 
higher in FHB resistant wheat cultivars Dream and Sumai3 than in a susceptible cultivar Lynx.

\section{Conclusions}

We have demonstrated that there are different patterns of gene induction in susceptible and resistant cultivars of wheat following $F$. graminearum inoculation and further infection. That may be due to variations in genetic backgrounds of wheat cultivars, which are probably due to different origins. The major finding of this study is that soil application of SA could prepare plants to confront the pathogen attack. The SA reduced disease rating in the susceptible and resistant cultivars and increased the expressions of genes and so proteins involved in plant defense and detoxification pathways. The SA-induced expression of $G l u-2$ and $P A L$ indicates that the attacked plant tried to respond to the pathogen through glucanase activity. We suggest the existence of a molecular pathway in the resistant cultivar through which the plant magnifies its defensive responses to pathogen attack by the use of Glu-2 and $P A L$ positive feedback loops. Hence, $P A L$ and $G l u$ could be considered for genetic engineering in F. graminearum-susceptible wheat cultivars because of their determined role in giving resistance to 'Sumai3'. These results provide a base in exploring mechanisms and regulations of FHB resistance in wheat; however, we emphasize that more investigations are necessary in order to find the upstream regulators of salicylic acid upon F. graminearum attack. Another unresolved question that remains to be answered is how an increased transcription of $G l u-2$ is compatible with our previous report of augmented content of callose ( $\beta$-1,3-glucan) in the resistant cultivar under pathogen treatment, as callose can be a target for glucanases. Can plant glucanases discriminate between the pathogen and their own glucan polymers?

\section{References}

Ancillo, G., Witte, B., Schmelzer, E., Kombrink, E.: A distinct member of the basic (class I) chitinase gene family in potato is specifically expressed in epidermal cells. - Plant mol. Biol. 39: $1137-1151,1999$.

Bai, G., Shaner, G.: Management and resistance in wheat and barley to Fusarium head blight 1. - Annu. Rev. Phytopathol. 42: 135-161, 2004.

Bienert, M.D., Siegmund, S.E., Drozak, A., Trombik, T., Bultreys, A., Baldwin, I.T., Boutry, M.: A pleiotropic drug resistance transporter in Nicotiana tabacum is involved in defense against the herbivore Manduca sexta. - Plant. J. 72: 745-757, 2012.

Bokshi, A., Morris, S., Deverall, B.: Effects of benzothiadiazole and acetylsalicylic acid on $\beta$-1,3-glucanase activity and disease resistance in potato. - Plant Pathol. 52: 22-27, 2003.

Bradford, M.M.: A rapid and sensitive method for the quantitation of microgram quantities of protein utilizing the principle of protein-dye binding. - Anal. Biochem. 72: 248-254, 1976.

Brederode, F.T., Linthorst, H.J.M., Bol, J.F.: Differential induction of acquired resistance and $\mathrm{PR}$ gene expression in tobacco by virus infection, ethephon treatment, UV light and wounding. - Plant mol. Biol. 17: 1117-1125, 1991.

Buchter, R., Stromberg, A., Schmelzer, E., Kombrink, E.: Primary structure and expression of acidic (class II) chitinase in potato. - Plant mol. Biol. 35: 749-761, 1997.

Chapple, C.: Molecular-genetic analysis of plant cytochrome P450-dependent monooxygenases. - Annu. Rev. Plant Biol. 49: 311-343, 1998.

Dempsey, D.A., Vlot, A.C., Wildermuth, M.C., Klessig, D.F.: Salicylic acid biosynthesis and metabolism. - In: Torii, K. (ed.): The Arabidopsis Book. Pp. 1-24. Amer. Soc. Plant Biologists, Rockville 2011.

Ding, C.K., Wang, C., Gross, K.C., Smith, D.L.: Jasmonate and salicylate induce the expression of pathogenesis-relatedprotein genes and increase resistance to chilling injury in tomato fruit. - Planta 214: 895-901, 2002.

Ding, L., Xu, H., Yi, H., Yang, L., Kong, Z., Zhang, L., Ma, Z.: Resistance to hemi-biotrophic $F$. graminearum infection is associated with coordinated and ordered expression of diverse defense signaling pathways. - PloS ONE 6: e19008, 2011.

Dong, X.: SA, JA, ethylene, and disease resistance in plants. Curr. Opin. Plant Biol. 1: 316-323, 1998.

Fraissinet-Tachet, L., Baltz, R., Chong, J., Kauffmann, S., Fritig, B., Saindrenan, P.: Two tobacco genes induced by infection, elicitor and salicylic acid encode glucosyl-transferases acting on phenylpropanoids and benzoic acid derivatives, including salicylic acid. - FEBS Lett. 437: 319-323, 1998.

Gottwald, S., Samans, B., Lück, S., Friedt, W.: Jasmonate and ethylene dependent defence gene expression and suppression of fungal virulence factors: two essential mechanisms of Fusarium head blight resistance in wheat? - BMC Genomics 13: 369, 2012.

Hwang, B.K., Sunwoo, J.Y., Kim, Y.J., Kim, B.S.: Accumulation of $\beta$-1,3-glucanase and chitinase isoforms, and salicylic acid in the DL- $\beta$-amino-n-butyric acid-induced resistance response of pepper stems to Phytophthora capsici. - Physiol. mol. Plant Pathol. 51: 305-322, 1997.

Hurkman, W.J., Tanaka, C.K.: Solubilization of plant membrane proteins for analysis by two-dimensional gel electrophoresis. - Plant Physiol. 81: 802-806, 1986.

Jia, Y., Martin, G.B.: Rapid transcript accumulation of pathogenesis-related genes during an incompatible interaction in bacterial speck disease-resistant tomato plants. -Plant mol. Biol. 40: 455-465, 1999.

Jones, J.D., Dangl, J.L.: The plant immune system. - Nature 444: 323-329, 2006.

Kang, J., Hwang, J.-U., Lee, M., Kim, Y.-Y., Assmann, S. M., Martinoia, E., Lee, Y.: PDR-type ABC transporter mediates cellular uptake of the phytohormone abscisic acid. - Proc. nat. Acad. Sci. USA 107: 2355-2360, 2010.

Kim, D.S., Hwang, B.K.: An important role of the pepper phenylalanine ammonia-lyase gene $(P A L 1)$ in salicylic aciddependent signaling of the defense response to microbial pathogens. - J. exp. Bot. 65: 2295-2306, 2014.

Kong, L., Anderson, J.M., Ohm, H.W.: Induction of wheat defense and stress-related genes in response to Fusarium graminearum. - Genome 48: 29-40, 2005.

Kosaka, A., Manickavelu, A., Kajihara, D., Nakagawa, H., Ban, T.: Altered gene expression profiles of wheat genotypes against Fusarium head blight. - Toxins 7: 604-620, 2015.

Lawton, K.A., Beck, J., Potter, S., Ward, E., Ryals, J.: Regulation of cucumber class III chitinase gene expression. - Mol. PlantMicrobe Interact. 7: 48-57, 1994.

Li, G., Yen, Y.; Jasmonate and ethylene signaling pathway may mediate Fusarium head blight resistance in wheat. - Crop Sci. 48:1888-1896, 2008.

Li, X., Zhang, J., Song, B., Li, H., Xu, H., Qu, B., Liao, Y.: 
Resistance to Fusarium head blight and seedling blight in wheat is associated with activation of a cytochrome P450 gene. - Phytopathoogy 100: 183-191, 2010.

Livak, K., Schmittgen, T.D.: Analysis of relative gene expression data using real-time quantitative PCR and the $2^{-\Delta \Delta C T}$ method. - Methods 25: 402-408, 2001.

Loake, G., Grant, M.: Salicylic acid in plant defence - the players and protagonists. - Curr. Opin. Plant Biol. 10: 466-472, 2007.

Makandar, R., Essig, J.S., Schapaugh, M.A., Trick, H.N., Shah, J.: Genetically engineered resistance to Fusarium head blight in wheat by expression of Arabidopsis NPR1. - Mol. PlantMicrobe Interact. 19: 123-129, 2006.

Makandar, R., Nalam, V., Chaturvedi, R., Jeannotte, R., Sparks, A.A., Shah, J.: Involvement of salicylate and jasmonate signaling pathways in Arabidopsis interaction with Fusarium graminearum. - Mol. Plant-Microbe Interact. 23: 861-870, 2010.

Makandar, R., Nalam, V.J., Lee, H., Trick, H.N., Dong, Y., Shah, J.: Salicylic acid regulates basal resistance to Fusarium head blight in wheat. - Mol. Plant-Microbe Interact. 25: 431-439, 2012.

Mitterbauer, R., Adam, G.: Saccharomyces cerevisiae and Arabidopsis thaliana: useful model systems for the identification of molecular mechanisms involved in resistance of plants to toxins. - In: Logrieco A., Bailey, J.A., Corazza L., Cooke B.M. (eds): Mycotoxins in Plant Disease. Pp. 699-703. Springer, Dordrecht 2002.

Moosawi-Jorf, S.A., Farrokhi-Nejad, R., Azimi, S., Afarin, S.: Study of Fusarium Head Blight of wheat in Khuzestan Province in Iran and reporting of Fusarium xylaroides as new causal agents for disease. - J. Agron. 6: 212, 2007.

Neuhoff, V., Arnold, N., Taube, D., Ehrhardt, W.: Improved staining of proteins in polyacrylamide gels including isoelectric focusing gels with clear background at nanogram sensitivity using Coomassie Brilliant Blue G-250 and R-250. - Electrophoresis 9: 255-262, 1988.

Nürnberger, T., Brunner, F., Kemmerling, B., Piater, L.: Innate immunity in plants and animals: striking similarities and obvious differences. - Immunol. Rev. 198: 249-266, 2004.

Paranidharan, V., Abu-Nada, Y., Hamzehzarghani, H., Kushalappa, A., Mamer, O., Dion, Y., Choiniere, L.: Resistance-related metabolites in wheat against Fusarium graminearum and the virulence factor deoxynivalenol (DON). - Botany 86: 1168-1179, 2008.

Rivera, M.E., Codina, J.C., Olea, F., De Vicente, A., PérezGarcía, A.: Differential expression of $\beta$-1, 3-glucanase in susceptible and resistant melon cultivars in response to infection by Sphaerotheca fusca. - Physiol. mol. Plant Pathol. 61: 257-265, 2002.

Sadat Ejtehad, R., Radjabian, T., Tafreshi, S.A.H.: Expression analysis of phenylalanine ammonia lyase gene and rosmarinic acid production in Salvia officinalis and Salvia virgata shoots under salicylic acid elicitation. - Appl. Biochem. Biotechnol. 176: 1846-1858, 2015.

Savitch, L.V., Subramaniam, R., Allard, G.C., Singh, J.: The GLK1 'regulon' encodes disease defense related proteins and confers resistance to Fusarium graminearum in Arabidopsis. - Biochem. Biophys. Res. Commun. 359: 234-238, 2007.

Silverman, P., Seskar, M., Kanter, D., Schweizer, P., Metraux, J.P., Raskin, I.: Salicylic acid in rice (biosynthesis, conjugation, and possible role). - Plant Physiol. 108: 633-639, 1995.

Sorahinobar, M., Niknam, V., Ebrahimzadeh, H., Soltanloo, H., Behmanesh, M., Tahmasebi Enferadi, S.: Central role of salicylic acid in resistance of wheat against Fusarium graminearum. - J. Plant Growth Regul. 35: 477-491, 2016.

Thulke, O., Conrath, U.: Salicylic acid has a dual role in the activation of defence-related genes in parsley. - Plant J. 14: 35-42, 1998.

Van Kan, J.A., Joosten, M.H., Wagemakers, C.A., Van den Berg-Velthuis, G.C., De Wit, P.J.: Differential accumulation of mRNAs encoding extracellular and intracellular PR proteins in tomato induced by virulent and avirulent races of Cladosporium fulvum. - Plant. mol. Biol. 20: 513-527, 1992.

Vidhyasekaran, P.: Salicylic acid signaling in plant innate immunity plant hormone signaling systems. - In: Vidhyasekaran P. (ed.): Plant Innate Immunity. Pp. 27-122. Springer, Dordrecht 2015.

Walter, S., Brennan, J.M., Arunachalam, C., Ansari, K.I., Hu, X., Khan, M.R., Egan, D.: Components of the gene network associated with genotype-dependent response of wheat to the Fusarium mycotoxin deoxynivalenol. - Funct. integr. Genomics 8: 421-427, 2008.

Wen, P.F., Chen, J.Y., Kong, W.F., Pan, Q.H., Wan, S.B., Huang, W.D.: Salicylic acid induced the expression of phenylalanine ammonia-lyase gene in grape berry. - Plant Sci. 169: 928-934, 2005.

Woloshuk, C.P., Meulenhoff, J.S., Sela-Buurlage, M., Van den Elzen, P., Cornelissen, B.: Pathogen-induced proteins with inhibitory activity toward Phytophthora infestans. - Plant Cell 3: 619-628, 1991.

Yu, G.Y., Muehlbauer, G.J.: Benzothiadiazole-induced gene expression in wheat spikes does not provide resistance to Fusarium head blight. - Physiol. mol. Plant Pathol. 59: 129136, 2001.

Zhang, H.-F., Li, Z.-H., Liu, J.-Y., Liu, T.-T., Wang, P., Fang, Y., Zhou, J., Cui, M.-Z., Gao, N., Tian, X.: Correlation of cytochrome P450 oxidoreductase expression with the expression of 10 isoforms of cytochrome $\mathrm{P} 450$ in human liver. - Drug Metab. Dispos. 44: 1193-1200, 2016. 